\title{
Activation of caspase-8 in 3-deazaadenosine-induced apoptosis of $U-937$ cells occurs downstream of caspase- 3 and caspase-9 without Fas receptor-ligand interaction
}

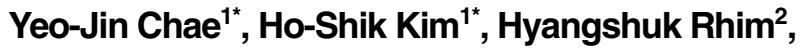 \\ Bo-Eun Kim ${ }^{1}$, Seong-Whan Jeong ${ }^{1}$ and \\ In-Kyung Kim ${ }^{1,3}$

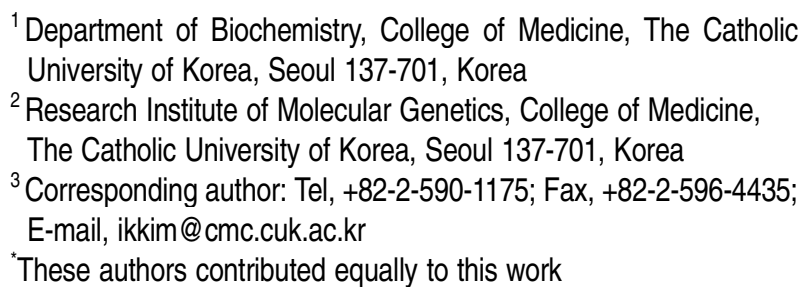

Accepted 10 December 2001

Abbreviations: DZA, 3-deazaadenosine; FADD, Fas-associated death domain; DD, death domain; DED, death effector domain; DISC, death-inducing signaling complex; Ado-Hcy, S-adenosylhomocysteine; DZA-Hcy, 3-deazaadenosylhomocysteine; BA, bongkrekic acid; CsA, cyclosporin A; MPTP, mitochondria permeability transition pore; ANT, adenine nucleotide translocator; VDAC, voltage-dependent anion channel

\begin{abstract}
3-Deazaadenosine (DZA), a cellular methylation blocker was reported to induce the caspase-3-like activities-dependent apoptosis in U-937 cells. In this study, we analyzed the activation pathway of the caspase cascade involved in the DZA-induced apoptosis using specific inhibitors of caspases. In the U-937 cells treated with DZA, cytochrome c release from mitochondria and subsequent activation of caspase-9, -8 and -3 were observed before the induction of apoptosis. ZDEVD-Fmk, a specific inhibitor of caspase-3, and zLEHD-Fmk, a specific inhibitor of caspase-9, prevented the activation of caspase- 8 but neither caspase-3 nor caspase- 9 , indicating that caspase- 8 is downstream of both caspase- 3 and caspase-9, which are activated by independent pathways. zVAD-Fmk, a universal inhibitor of caspases, kept the caspase-3 from being activated but not caspase-9. Moreover, ZB4, an antagonistic Fasantibody, exerted no effect on the activation of caspase-8 and induction of apoptosis by DZA. In addition, zVAD-Fmk and mitochondrial permeability transition pore (MPTP) inhibitors such as cyclosporin $A$ (CsA) and bongkrekic acid (BA) did not
\end{abstract}

block the release of cytochrome c from mitochondria. Taken together, these results suggest that in the DZA-induced apoptosis, caspase-8 may serve as an executioner caspase and be activated downstream of both caspase-3 and caspase-9, independently of Fas receptor-ligand interaction. And caspase-3 seems to be activated by other caspses including IETDase-like enzyme and caspse-9 seems to be activated by cytochrome c released from mitochondria without the involvement of caspases and CsA- and BA- inhibitory MPTP.

Keywords: 3-deazaadenosine, caspase, caspase inhibitor, apoptosis

\section{Introduction}

Apoptosis, a physiological process of cell death, is critical for the normal development and function of multicellular organisms (Andreas et al., 2000). Apoptosis is characterized by morphological changes including chromatin condensation, cytoplasmic shrinkage, and plasma membrane blebbing and biochemical changes including internucleosomal DNA cleavage (Kerr et al., 1972; Wyllie et al., 1980) and randomization of the distribution of phosphatidylserine (PS) between the inner and outer leaflets of the plasma membrane (Fadok and Henson, 1998). These changes are elicited by a broad range of physiological or experimentally applied death stimuli such as DNA damage, UV radiation, ionizing radiation and oxidative stress, and are observed in cells from diverse tissue types and species (Vaux and Strasser, 1996).

Caspase is known to be essential for apoptosis in a variety of species and models (Kumar and Lavin, 1996). Because caspase activities can be detected in all cells undergoing apoptosis, regardless of their origin or death stimuli, and they bring about most of visible changes that characterize apoptotic cell death, caspases can be thought as the central executioners of apoptosis (Cohen, 1997). Indeed, eliminating caspase activity, either by mutation or by the use of small pharmacological inhibitors, slowed down or even prevented apoptosis (Earnshaw et al., 1999). Caspases are synthesized as enzymatically inert zymogens and need to be cleaved autocatalytically or by other caspases to be activated (Stennicke and Salvesen, 1998). Caspases are divided into subfamilies based on their substrate preference, extent of sequence identity, and structural similarities. 
With a view of their functions, caspases can be classified into cytokine activators such as caspase-1, -4 , and -5 , apoptotic initiators such as caspase-8, -9, -10, and -2 , and apoptotic executioners such as caspase-3, -6 , and -7 . Initiator caspases can activate executioner caspases, which in turn cleave diverse cellular substrates including gelsolin, fodrin, poly (ADP-ribose) polymerase (PARP), and ICAD/DFF45 resulting in characteristic changes of apoptosis. Thus, it is thought that there is a hierarchical relation between initiator caspases and executioner caspases (Cohen, 1997). The hierarchical model of caspase activation was well established in the two principal pathways of apoptosis induced by Fas receptor and anticancer drugs (Cryns and Yuan, 1998; Hengartner, 2000).

Trimerization of Fas receptor induced by Fas ligand recruits multiple procaspase-8 forming the death-inducing signaling complex (DISC) via the adapter molecule Fas-associated death domain (FADD) protein. FADD contains death domain (DD) and death effector domain (DED), through which FADD binds to Fas and procaspase-8, respectively, thereby linking Fas and procaspase-8 (Nagata, 1997). Procaspase-8, upon forming DISC, is activated autoproteolytically (Muzio et al., 1998). The activated caspase-8 directly cleaves procaspase-3, an executioner caspase (Stennicke et al., 1998). In the meanwhile, DNA-damaging agents such as anticancer drugs or irradiation induces apoptosis initiated at the mitochondrion by the release of cytochrome c, the mechanisms of which is not clarified yet (Sun et al., 1999; Tepper et al., 1999). The cytochrome c in the cytosol binds to apoptotic protease activating factor (Apaf)-1, and the binding recruits and activates procaspase-9 (Stennicke et al., 1999). The activated caspase-9, in turn, also activates caspase-3 (Slee et al., 1999; Hengartner, 2000). In some cells, caspase-8 activated by Fas truncates Bid, which translocates to mitochondria and stimulates the release of cytochrome c there. Thus, death signal generated by Fas can be transmitted to mitochondria, making up an amplification loop between mitochondria and caspases (Scaffidi et al., 1998).

3-Deazaadenosine (DZA) which was developed as a potent inhibitor of S-adenosylhomocysteine (Ado-Hcy) hydrolase (Chiang et al., 1977) serves as both an inhibitor and a substrate of this enzyme resulting in the accumulation of S-Ado-Hcy and 3-deazaadenosylhomocysteine (DZA-Hcy) (Chiang et al., 1977; Aksamit et al., 1982). DZA inhibits monocyte and neutrophil chemotaxis (Aksamit et al., 1983), lymphocyte-mediated tumor cell lysis (Zimmerman et al., 1978), macrophage phagocytosis and microfilament disorganization (Medzihradsky, 1984), histamine release by basophils (Morita et al., 1982), macrophage lysosomal secretion (Riches et al., 1985), and superoxide anion generation (Yagawa et al., 1986). In addition, it has anti-human immunodeficiency virus (HIV) activity (Flexner et al., 1992), anti-inflammatory effect (Krenitsky et al., 1986), and inhibitory effects of cytokine expression including tumor necrosis factor- $\alpha$ (TNF- $\alpha$ ) and interleukin-1 $\beta$ (IL-1) (Jeong et al.,

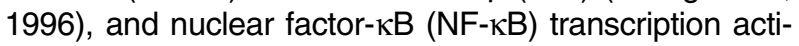
vity (Jeong et al., 1999).

Recently, it has been demonstrated that DZA induced apoptosis in murine and human leukemic cells dependent on the activation of caspase-3-like activities, although the upstream events resulting in the activation of caspase-3-like activities remains to be clarified (Kim et al., 1997; Kim et al., 2000). In this study, we examined the activation pathway of the caspase cascade in the DZAinduced apoptosis.

\section{Materials and Methods}

\section{Materials and reagents}

3-Deazaadenosine (DZA) is a kind gift of Dr. Chiang of the Walter Reed Army Institute of Research, Washington DC. Caspase inhibitors were purchased from BioRad Laboratories (Hercules, CA). Protease inhibitor cocktail was from Roche Molecular Biochemicals (Mannheim, Germany). Bongkrekic acid (BA) and cyclosporin A (CsA) were from Calbiochem-Novabiochem (San Diego, CA). Agonistic anti-Fas antibody $(\mathrm{CH} 11)$ and antagonistic antiFas antibody (ZB4) were from Upstate Biotechnology (Lexington, KY). 3-(4,5-Dimethylthiazol-2-yl) 2,5-diphenyltetrazolium bromide (MTT) was from Sigma (St. Louis, $\mathrm{MO}$ ). All other reagents were of ACS or molecular biology grade, and from Sigma, otherwise specified.

\section{Cell culture and viability assay}

Human monocytic macrophage U-937 cells were maintained in RPMI 1640 media supplemented with 10\% heat-inactivated fetal bovine serum (Hyclone Laboratories Inc., Logan, UT) and 100 units $/ \mathrm{ml}$ of penicillin/ streptomycin in a humidified atmosphere of $95 \%$ air and $5 \% \mathrm{CO}_{2}$. To observe the effect of DZA on the growth of U-937 cells, cell viability was determined by MTT assay (Mossmann, 1983). Cells were seeded at a density of $1 \times 10^{4} /$ well in 96 -well culture plates and then treated with indicated concentrations of DZA, finally adjusting media volume to $100 \mu \mathrm{l}$. After incubation of indicated times, $10 \mu \mathrm{l}$ of MTT reagent (final concentration; $500 \mu \mathrm{g} /$ $\mathrm{ml}$ ) was added to each well. Three hours later, cells were harvested and centrifuged to pellet MTT crystals. MTT crystals were dissolved with isopropanol containing $0.04 \mathrm{~N}$ of $\mathrm{HCl}$ and the absorbance was measured at $570 \mathrm{~nm}$.

\section{Evaluation of apoptosis}

Induction of apoptosis was determined by fragmentation of genomic DNA through agarose gel electrophoresis 
and fluorescence microscopic examination of cells stained with Hoechst 33342. Genomic DNA of cells treated with DZA or DZA plus other compounds for desired times was extracted using DNA extraction buffer $(5 \mathrm{mM}$ Tris-Cl, 20 mM EDTA, pH 8.0, 1\% sodium dodecyl sulfate (SDS), $50 \mu \mathrm{g} / \mathrm{ml}$ proteinase $\mathrm{K}$ ) and extraction with phenol-ethanol. DNA pellet was dissolved in TE buffer (10 mM Tris-Cl, 1 mM EDTA, pH 8.0) containing $20 \mu \mathrm{g} /$ $\mathrm{ml}$ of RNase $\mathrm{A}$, and incubated at $37^{\circ} \mathrm{C}$ for $1 \mathrm{~h}$. Five micrograms of DNA was separated on $2 \%$ agarose gels with $0.5 \times$ TAE (20 mM Tris-acetate, $1 \mathrm{mM}$ EDTA). Ethidium bromide (EtBr)-stained DNA in the gel was visualized under UV light and photographed. To investigate morphological changes of nuclei in U-937 cells, cells were incubated in the presence of Hoechst 33342 (10 $\mu \mathrm{M})$ for $10 \mathrm{~min}$ at $37^{\circ} \mathrm{C}$. After being washed with phosphate-buffered saline (PBS), cells were examined under fluorescence microscope (Carl Zeiss, Oberkochen, Germany).

\section{Antibodies}

Mouse anti-caspase-3 antibody and mouse anti-caspase- 9 antibody were purchased from Transduction laboratories (Lexington, KY). Rabbit anti-caspase-8 antibody was from Upstate Biotechnology (Lake Placid, NY). Mouse anti-cytochrome $c$ antibody and mouse anti-porin antibody were from Pharmingen (San Diego, CA). Horseradish peroxidase-conjugated secondary antibodies against rabbit or mouse IgG were from Sigma.

\section{Western blot analysis}

Cells treated as indicated were lysed with RIPA buffer (1\% Triton X-100, 20 mM Tris-Cl, pH 7.5, 150 mM NaCl, $0.5 \%$ deoxycholate, $0.1 \%$ SDS, $1 \mathrm{mM}$ EDTA) containing protease inhibitor cocktail. Protein concentrations were measured by bicinchoninic acid method. Fifty micrograms of protein were resolved on 10\% SDS-polyacrylamide gel electrophoresis (PAGE) and electrotransferred onto nitrocellulose membranes (Schleicher and Shuell, Dassel, Germany) in transfer buffer (25 mM Tris base, $193 \mathrm{mM}$ glycine, 20\% methanol). The membrane was soaked in 5\% nonfat dried milk in trisbuffered saline (TBS; $10 \mathrm{mM}$ Tris-Cl, $\mathrm{pH} 7.5,150 \mathrm{mM}$ $\mathrm{NaCl}$ ) for $30 \mathrm{~min}$ and then incubated with primary antibodies in blocking solution at $4^{\circ} \mathrm{C}$ overnight, followed by extensive washing with TTBS (TBS containing $0.05 \%$ Tween-20). Membranes were then incubated with peroxidase-conjugated secondary antibodies (goat antimouse or -rabbit IgG antibody) in blocking solution at room temperature, followed by washing with TTBS. Proteins were detected using the enhanced chemiluminescence Western blotting detection system (AmershamPharmacia, Buckinghamshire, UK).

\section{Subcellular fractionation}

Subcellular fractionation was performed according to the method of Akao et al. (1994). Briefly, harvested cells were washed twice with ice-cold PBS and then resuspended in hypotonic buffer (10 mM HEPES, $10 \mathrm{mM}$ $\mathrm{MgCl}_{2}, 42 \mathrm{mM} \mathrm{KCl}$ ). Cells were passed through a $30-$ gauge syringe and centrifuged at $1,000 \mathrm{rpm}$ for $5 \mathrm{~min}$ to remove unlysed cells and nuclei. The supernatant was further centrifuged at $15,000 \mathrm{rpm}$ for $15 \mathrm{~min}$ at $4^{\circ} \mathrm{C}$. The resulted pellet is heavy membrane fraction used as the mitochondrial fraction. The supernatant was ultracentrifuged at $100,000 \mathrm{~g}$ for $90 \mathrm{~min}$. The pellet is light membrane fraction and the supernatant is cytosolic fraction.

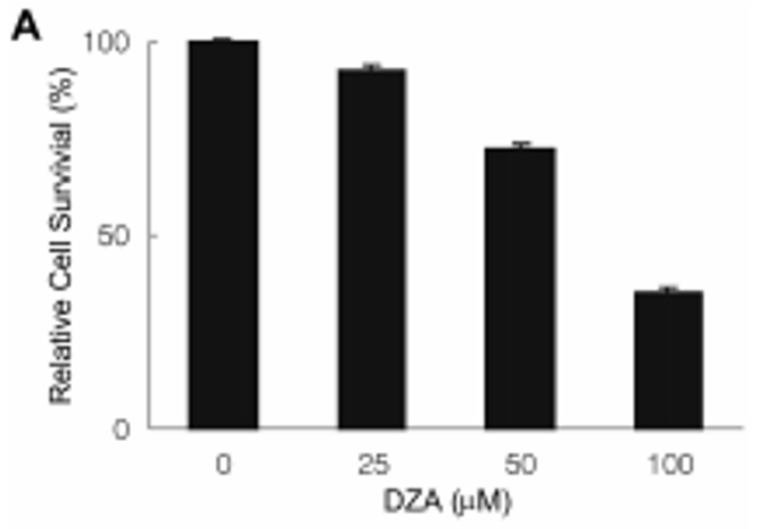

B

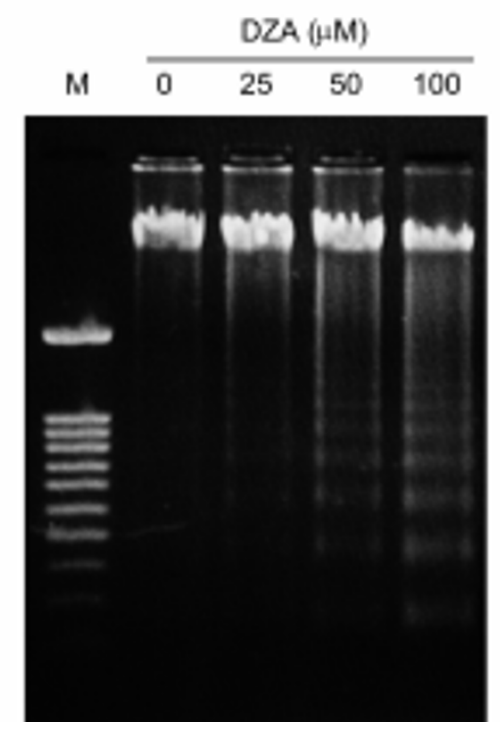

Figure 1. DZA-induced growth inhibition and DNA fragmentation in U-937 cells. (A) U-937 cells $\left(1 \times 10^{4}\right)$ were treated with the indicated concentrations of DZA. After $8 \mathrm{~h}$, MTT assay was performed as described in Materials and Methods and expressed as relative cell survival which means the percent of cell viability of the treated cells to that of the cells without treatment. The data were expressed as mean \pm S.D. of three independent experiments performed in triplicate. (B) Genomic DNA of cells treated with indicated concentrations of DZA was extracted as described in Materials and Methods. Extracted genomic DNA were separated into 2\% agarose gel. M: 100 bp DNA ladder marker. 
A
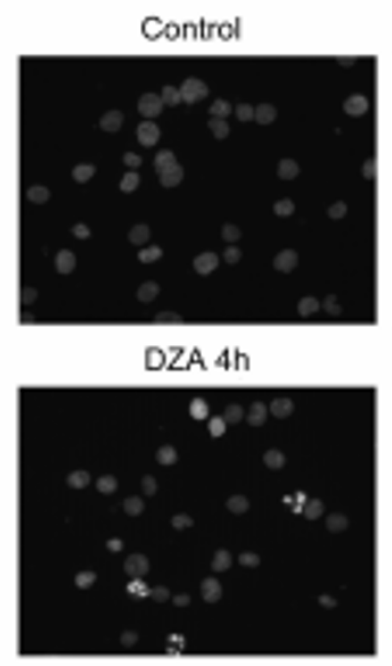

DZA 8h

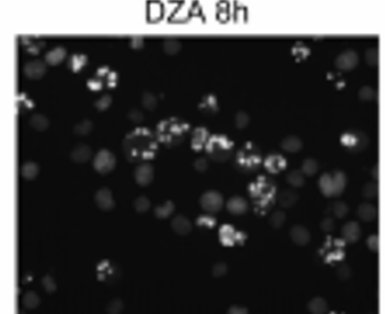

B

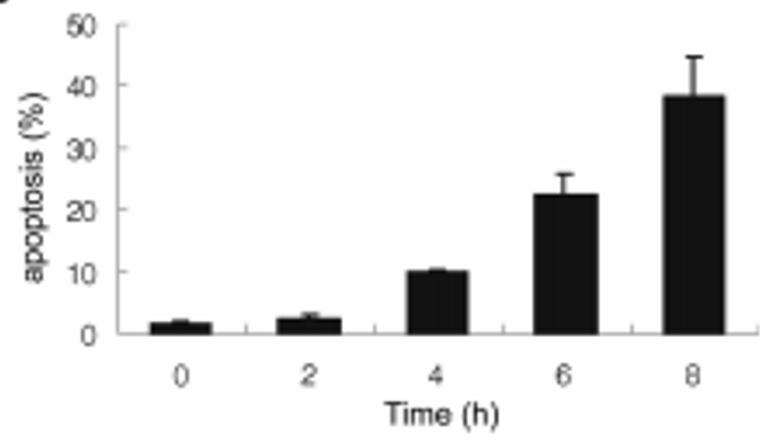

Figure 2. DZA-induced apoptosis in U-937 cells. (A) Cells treated with 100 $\mu \mathrm{M}$ of DZA for indicated times were stained with Hoechst $33342(10 \mu \mathrm{M})$ for $10 \mathrm{~min}$ and observed under fluorescence microscope. (B) The number of the apoptotic cells were counted under fluorescence microscope. The data were expressed as mean \pm S.D. of three independent experiments performed in triplicate.

\section{Results}

\section{Induction of U-937 cell apoptosis by DZA}

DZA treatment of U-937 cells resulted in cell growth inhibition and fragmentation of nuclear DNA in a dosedependent manner suggesting that the growth inhibitory effect of DZA is attributable to apoptosis (Figure 1). Fluorescence microscopic examination of Hoechst 33342stained DZA-treated cells showed condensed and fragmented nuclei, characteristic features of apoptosis
A

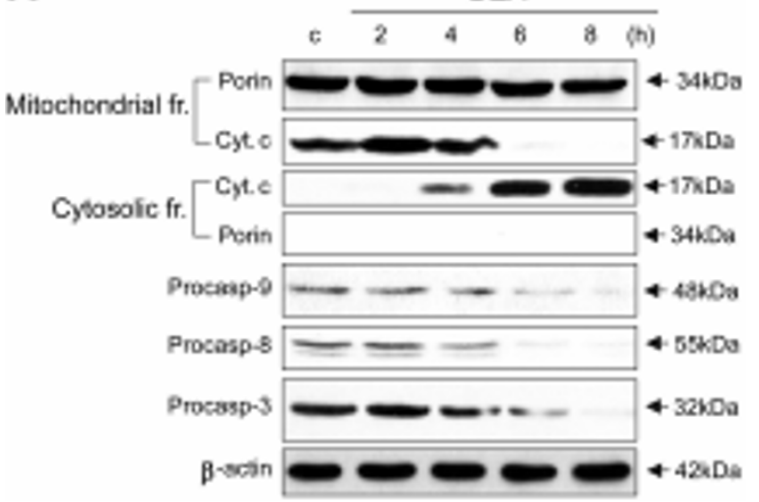

B

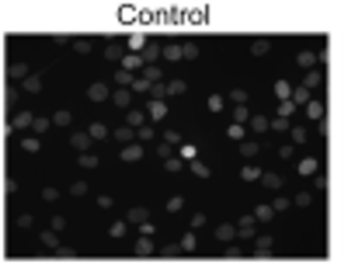

VAD $+D Z A$
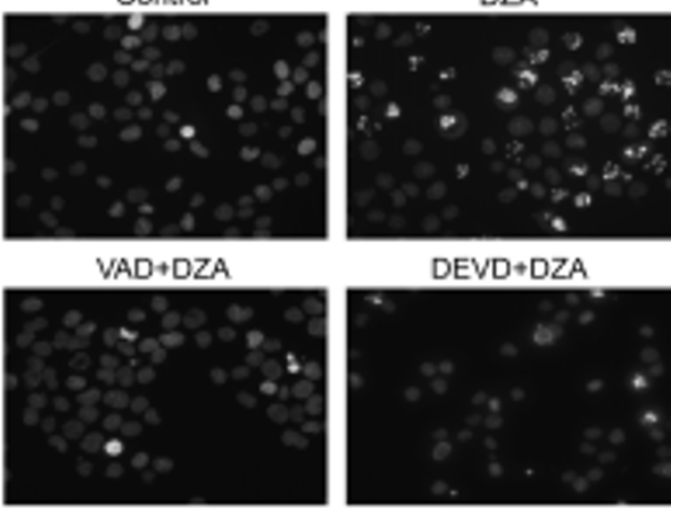

$\mathrm{DEVD}+\mathrm{DZA}$
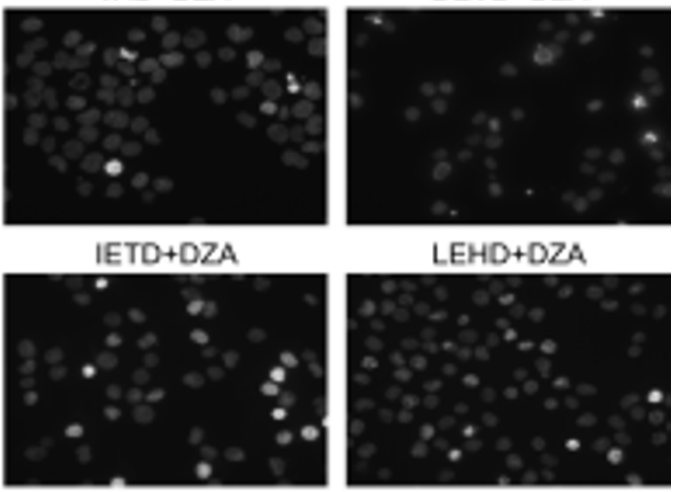

C

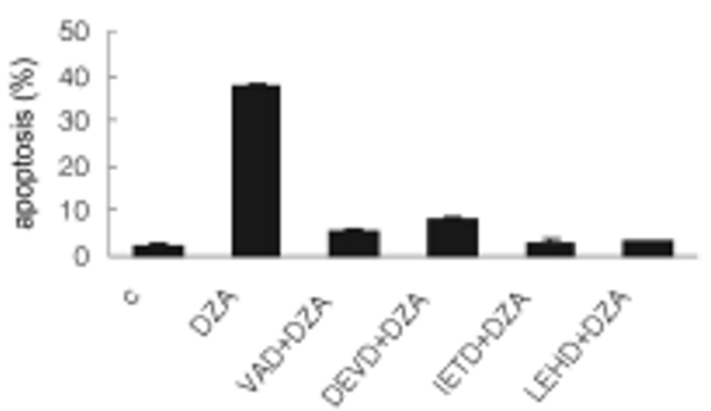

Figure 3. Activation of caspases cascade induced by DZA. (A) Subcellular fractions (fr) or total cell lysates of U-937 cells treated with $100 \mu \mathrm{M}$ of DZA were subjected to $15 \%$ or $10 \%$ SDS-PAGE respectively, and then Western blot analysis was performed with anti-cytochrome $\mathrm{C}$ antibody and anticaspases-9, $-8,-3$ antibodies as described in Material and Methods. (B), (C) Cells were incubated in the absence or presence of caspase inhibitors (100 $\mu \mathrm{M}$ of zVAD-Fmk, $200 \mu \mathrm{M}$ of zDEVD-Fmk, $200 \mu \mathrm{M}$ of zIETD-Fmk, $400 \mu \mathrm{M}$ of ZLEHD-Fmk) for $1 \mathrm{~h}$ and treated for $8 \mathrm{~h}$ further with $100 \mu \mathrm{M}$ of DZA. Cells were stained with Hoechst $33342(10 \mu \mathrm{M})$ and examined under fluorescence microscope $(B)$ and the number of apoptotic cells were counted $(C)$. The data were expressed as mean \pm S.D. of three independent experiments performed in triplicate. 
(Figure 2a). The level of apoptosis was highest in U-937 cells treated with $100 \mu \mathrm{M}$ of DZA for $8 \mathrm{~h}$ (Figure 2b). Thus, $100 \mu \mathrm{M}$ concentration of DZA was used in all subsequent experiments.

\section{Release of cytochrome $c$ and activation of caspase cascade induced by DZA}

Cytochrome c release from mitochondria and the activation of caspase- $9,-8$ and -3 in the U-937 cells treated with DZA was examined by Western blot analysis. As shown in Figure 3, the cytochrome $c$ was released to cytosol post $4 \mathrm{~h}$ DZA treatment and activation of caspase- $9,-8$ and -3 was also observed. Porin was used as a reference mitochondrial protein for subcellular fractionation. The early cellular apoptotic responses associated with cytochrome $\mathrm{C}$ release post $4 \mathrm{~h}$ DZA-treatment suggest that possible relationship between cytochrome c release and caspase cascade in U-937 cells affected by DZA.

To examine the involvement of caspases in this system, the effect of specific caspase inhibitors was tested on apoptosis of the U-937 cells in the presence or absence of DZA. Pretreatment of cells with caspase inhibitors: a universal caspase inhibitor zVAD-Fmk, a caspase-3 inhibitor zDEVD-Fmk, a caspase-8 inhibitor zIETD-Fmk, and a caspase-9 inhibitor zLEHD-Fmk, blocked nuclear fragmentation and condensation induced by DZA (Figure $3 B$ and $C$ ). Thus, the activation of caspase- $9,-8$ and -3 seems to be necessary to this apoptosis.

\section{Effect of caspase inhibitors on DZA-induced activa- tion of caspase-9, -8 and-3}

To determine possible steps involved in DZA-induced caspase activation associated with cellular apoptosis, the effect of specific individual caspase inhibitor on the activation of caspase- $9,-8$, and -3 was examined by Western blot analysis (Figure 4). zDEVD-Fmk and zLEHDFmk prevented the activation of caspase-8, but not the activation of caspase- 3 and caspase- 9 indicating that caspase- 8 is downstream of caspase- 3 and caspase- 9 which are activated by independent pathways. The activation of caspase-3 was inhibited weakly by zIETDFmk but almost completely by zVAD-Fmk, suggesting that other caspase activities including IETDase activity seem to be present upstream of caspase-3. Being consistent with other reports that caspase-9 is activated directly by cytochrome c (Stennicke et al., 1998), caspase inhibitors used exerted no effect on the activation of caspase- 9 ruling out the involvement of caspases on the activation of itself.

\section{The effect of antagonistic Fas-Ab (ZB4) on DZA- induced caspase-8 activation}

Chemotherapeutic agents such as doxorubicin is reported to activate caspase-8 by inducing Fas receptorligand interaction, preceding the activation of caspase-3 (Friesen et al., 1996; Fulda et al., 2000). To study whether the Fas receptor-ligand interaction is involved in the DZA induced caspase- 8 activation, U-937 cells
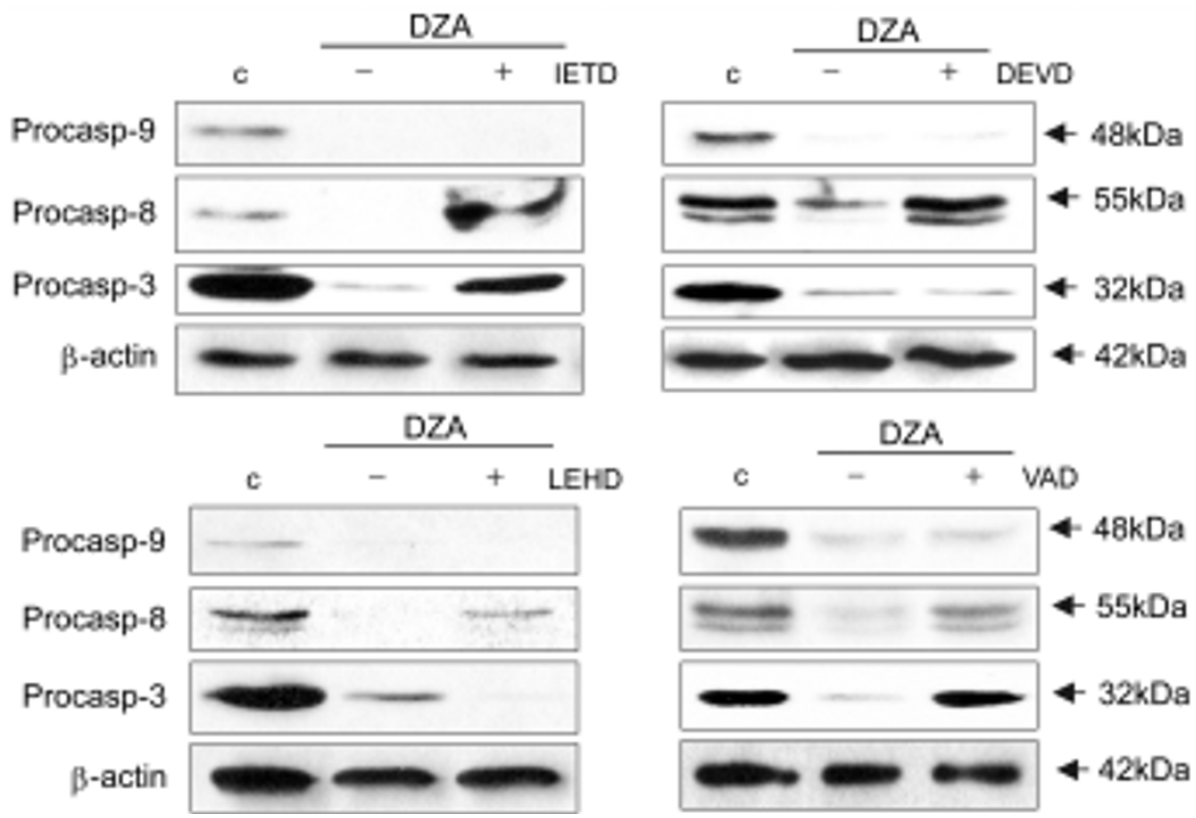

Figure 4. The effect of specific caspase inhibitors on the activation of caspase $-9,-8,-3$ induced by DZA. Cells were pretreated for $1 \mathrm{~h}$ with caspase inhibitors $(100 \mu \mathrm{M}$ of zVAD-Fmk, $200 \mu \mathrm{M}$ of zDEVD-Fmk, $200 \mu \mathrm{M}$ of zIETD-Fmk, $400 \mu \mathrm{M}$ of ZLEHD-Fmk) and further incubated for $8 \mathrm{~h}$ in the presence of DZA (100 $\mu \mathrm{M})$. Cell lysates were subjected to $10 \%$ SDS-PAGE and then Western blot analysis was performed with anti-caspases-9, -8 , and -3 antibodies. 
A

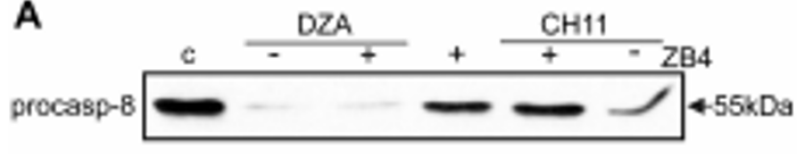

B

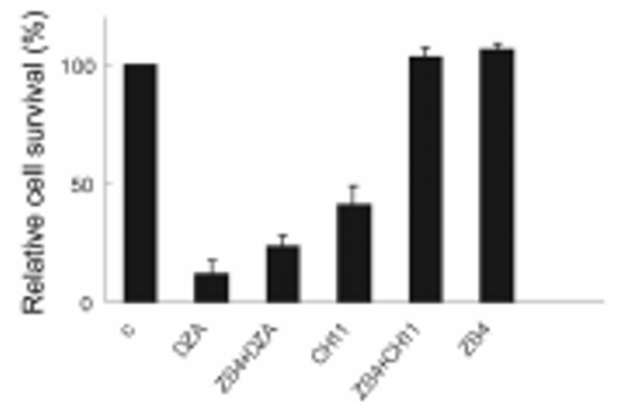

Figure 5. The effect of antagonistic Fas-Ab (ZB4) on the activation of caspase-8 induced by DZA. (A) Cells pretreated for $1 \mathrm{~h}$ with $500 \mathrm{ng} / \mathrm{ml}$ of ZB4 or media alone were incubated for $8 \mathrm{~h}$ with DZA $(100 \mu \mathrm{M})$ or $\mathrm{CH} 11$ (agonistic Fas-Ab; $1 \mu \mathrm{g} / \mathrm{ml}$ ). Cell lysates were subjected to 10\% SDS-PAGE and then Western blot analysis was performed with anti-caspase-8 antibody. (B) Cells $\left(1 \times 10^{4}\right)$ were treated as the Figure $5(\mathrm{~A})$ legend. Cell viability was determined by MTT assay and expressed as relative cell survival which means the percent of cell viability of the treated cells to that of the cells without treatment. The data were expressed as mean \pm S.D. of three independent experiments performed in triplicate.

were treated with the antagonistic Fas-Ab (ZB4) before the addition of DZA. ZB4 inhibited the caspase-8 activation and reduction of cell viability induced by agonistic Fas-Ab (CH11), but it exerted no effect on the DZA induced cellular events (Figure 5). Thus, the Fas receptor-ligand system does not appear to be involved in the activation of caspase- 8 and the apoptosis induced by DZA, confirming that the caspase- 8 activation is downstream of caspase-3.

\section{Effect of bongkrekic acid (BA), cyclosporin A (CsA), and ZVAD-Fmk on DZA-induced cytochrome $c$ release}

CsA and BA, known inhibitors of cytochrome $c$ release by closing the mitochondria permeability transition pore (MPTP) (Crompton, 1999; Jacotot et al., 2000) induce prevention of apoptosis in several systems. The effects of BA, CsA and zVAD-Fmk on the release of cytochrome $c$ induced by DZA was examined to understand the mechanism involved in the release of cytochrome $\mathrm{C}$ and its contribution to apoptosis. Neither BA nor CsA altered the translocation of cytochrome $\mathrm{c}$ from mitochondria to cytosol (Figure 6) and apoptosis (data not shown). zVAD-Fmk which induced prevention of apoptosis did not affect the release of cytochrome $\mathrm{c}$. These results suggest that DZA stimulate the release of cytochrome $c$ through other pathways than CsA- or BAinhibitory MPTP, and cytochrome $c$ release is upstream and independent of caspase activation.

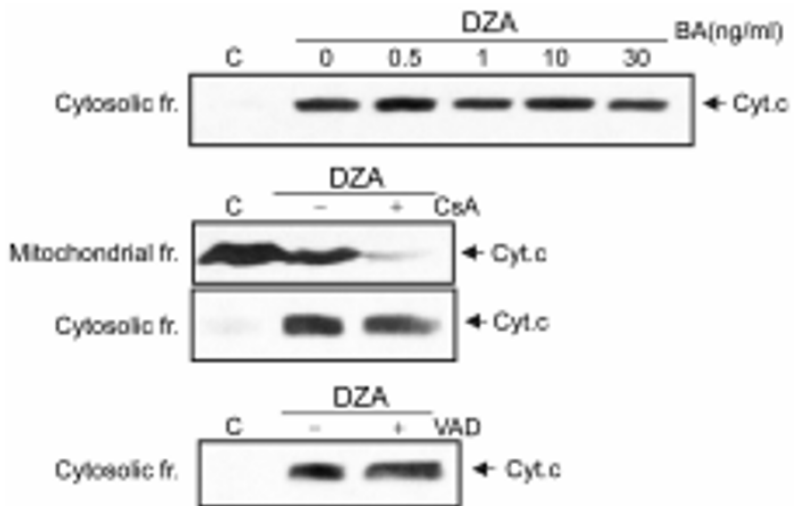

Figure 6. The effect of BA, CsA, and ZVAD-Fmk on the release of cytochrome $\mathrm{C}$ induced by DZA. Cells pretreated for $1 \mathrm{~h}$ with indicated concentrations of BA, $20 \mu \mathrm{M}$ of CsA or $200 \mu \mathrm{M}$ of ZVAD-Fmk were incubated for $8 \mathrm{~h}$ with $100 \mu \mathrm{M}$ of DZA. Aliquots of subcellular fractions or total cell lysates were separated by $15 \%$ SDS-PAGE and subjected to Western blot analysis.

\section{Discussion}

DZA-induced apoptosis of human leukemic cells was caused by activating caspase-3-like activities (Kim et al., 2000). In this study, the activation pathway of caspase cascade in the DZA-induced apoptosis was investigated by analyzing the effects of specific caspase inhibitors on the activation of caspase- $9,-8$ and -3 . DZA stimulated the release of cytochrome c, activation of caspase-9, -8 and -3 before inducing apoptosis. zDEVD-Fmk, a caspase-3 inhibitor, and zLEHD-Fmk, a caspase- 9 inhibitor, blocked the activation of caspase-8 but neither caspase- 3 nor caspase- 9 , suggesting that caspase- 8 is activated by caspase- 9 and capase- 3 which are activated independently. The activation of caspase-3 was completely abolished by a universal inhibitor of caspases zVAD-Fmk, and slightly by a caspase-8 inhibitor zIETDFmk, indicating that caspase- 3 is activated by other active caspases including caspase-8-like enzymes but not caspase-8, because at this concentration of ZIETDFmk, the activation of caspase-8 was completely prevented. Caspase inhibitors did not alter the activity of caspase-9 and the release of cytochrome c. So, it appears that DZA-induced cytochrome $c$ release is independent of caspase activities except caspase-9 that is activated directly by released cytochrome c. These data can be summarized schematically as shown in Figure 7. DZA activates two pathways; one is caspaseindependent cytochrome $c$ release and subsequent activation of caspase-9, and the other is caspase-dependent activation of caspase-3. The activated caspase-3 and caspase-9, in turn, activates caspase-8. Because zLEHD-Fmk and zDEVD-Fmk, which inhibited the activation of caspase-8 but neither caspase-3 nor caspase9, and zIETD-Fmk prevented apoptosis, caspase-8 


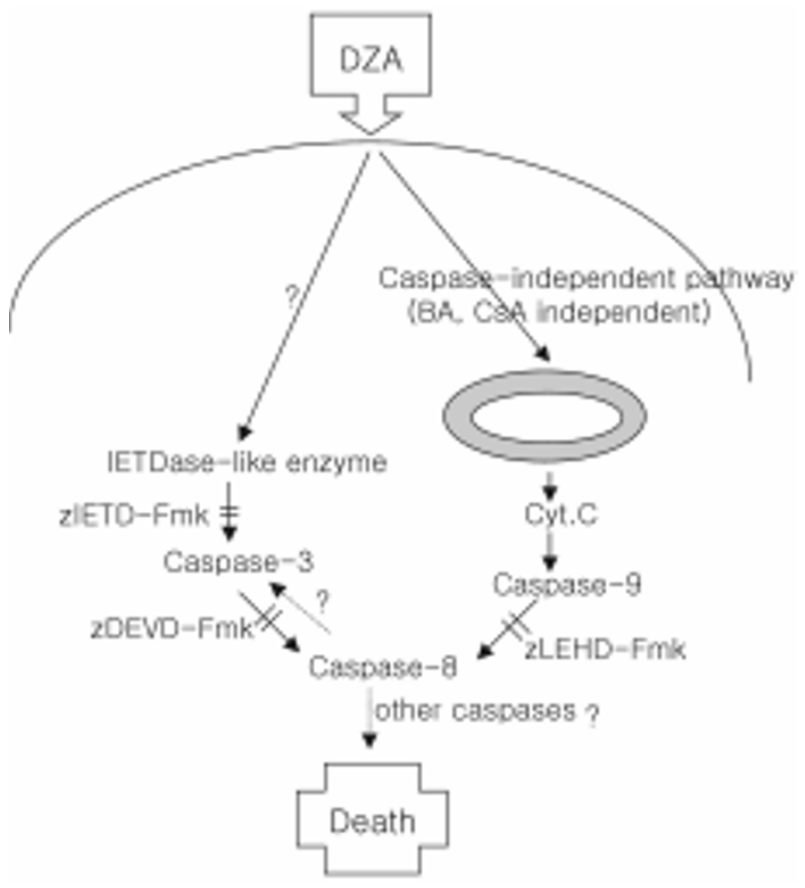

Figure 7. The schematic diagram of caspase cascade activated by DZA.

seems to act as an executioner caspase in the DZAinduced apoptosis.

In general, caspase-8 acts as an upstream caspase relaying death signal generated by Fas receptor-ligand interaction to downstream caspase-3, directly cleaving procaspase-3 or to mitochondria via truncated Bid (Kruidering and Evan, 2000). In addition, it has been shown that caspase-8 can process many other caspases (Srinivasula et al., 1996), implying that caspase-8 may act as an initiator caspase. However, in the apoptosis induced by anticancer drugs, the role and location of caspase-8 is controversial. Doxorubicin, cisplatin and VP-16 induced apoptosis in human leukemic and neuroblastoma cells by activating Fas receptorligand interaction suggesting the role of caspase-8 as an initiator caspase (Friesen et al., 1996; Fulda et al., 1997). But, Fas receptor-ligand interaction was not involved in the apoptosis and the activation of caspase8 of leukemic cells such as HL-60, K562, and U-937 cells induced by anticancer drugs, although the role of caspase- 8 was not definitely determined (McGahon et al., 1998; Tolomeo et al., 1998). Recently, caspase-8 as an executioner caspase in the anticancer drug-induced apoptosis was reported (Engels et al., 2000). The discrepancies about the role of caspase- 8 may be related to cell type differences rather than anticancer agent itself, since doxorubicin induces Fas-dependent (Friesen et al., 1996) and -independent apoptosis (McGahon et al., 1998). In cells with high levels of caspase-8 and inducible expression of Fas and Fas ligand, anticancer drugs might induce apoptosis by way of Fas receptor-ligand system. In other cell lines with low levels of caspase-8 and are incapable of inducing Fas and Fas ligand, Fas receptor-ligand system seems not to be involved in the apoptosis by anticancer drugs. U-937 cell line used in this experiment expresses Fas and Fas ligand, the levels of which were not changed by DZA (data not shown) being consistent with a previous report (McGahon et al., 1998). So, the apoptosis and the activation of caspase8 in U-937 cells might be mediated by Fas-independent pathway. As expected, antagonistic Fas-Ab (ZB4) exerted no effects on the apoptosis and the activation of caspase-8 in U-937 cells induced by DZA. Because it was not examined the effect of DZA on other cell lines having Fas-dependent apoptotic mechanism, we don't know yet whether the apoptotic mechanism in U-937 cells induced by DZA is cell-type specific.

In these experiments, in contrast to the fact that caspase-8 is an upstream caspase and can activate caspase3 , by directly cleaving procaspase- 3 , and caspase- 9 by stimulating the release of cytochrome $c$ from mitochondria, caspase-8 was activated downstream of caspase3 and caspase-9. Although the mechanism involved in the activation of caspase- 8 by caspase- 3 or -9 is not clarified in this study, this finding is consistent with other reports that caspase-8 is a downstream effector of caspase-3 or -9 (Slee et al., 1999; Wieder et al., 2001). Since zDEVD-Fmk and zLEHD-Fmk, inhibitors of caspase-3 and caspase-9, respectively, blocked the processing of procaspase-8 and apoptosis, caspase-8 needs both caspase- 3 and caspase- 9 to be activated.

It has been suggested that permeability transition, and a subsequent drop in mitochondrial membrane potential, is a principal mechanism by which cytochrome $\mathrm{c}$ is released from the mitochondria into the cytosol during apoptosis (Bernardi et al., 1999). Thus, inhibitors of mitochondrial permeability transition (MPT) such as BA and CsA, are able to inhibit apoptosis induced by cytochrome c-involved caspase cascade (Crompton, 1999; Jacotot et al., 2000). The adenine nucleotide translocator (ANT), the voltage-dependent anion channel (VDAC), Bax, and cyclophilin D are known to constitute the MPTP at the mitochondrial inner and outer membrane contact region (Beutner et al., 1998; Woodfield et al., 1998). BA, a ligand of ANT and CsA, a ligand of cyclophilin $\mathrm{D}$, inhibit pore formation by the ANT, thereby closing the MPTP (Kroemer and Reed, 2000).

In these experiments, the release of cytochrome $c$ in U-937 cells was stimulated by DZA and was not affected by BA and CsA. Therefore, it seems that MPTP and permeability transition may not involved in the release of cytochrome $c$ by DZA like didemnin B (Grubb et al., 2001). But, because we did not directly measure the mitochondrial membrane potential, it cannot be definitely concluded whether the involvement of permeability transition. Recently, Genini et al. (2000) reported that deoxyadenosine analogs such as 2-deoxy- 
adenosine, 2-chloro-2-deoxyadenosine and 2-chloro-2fluorodeoxyadenosine directly disrupted the integrity of mitochondria, suggesting the binding of deoxyadenosine analogs and the ANT, before inducing apoptosis in primary chronic lymphocytic leukemic cells. Therefore, it can be postulated, then, that DZA may bind to the ANT or other mitochondrial proteins not affected by BA or CsA and stimulate the release of cytochrome $c$, although more intensive experiments should be performed to understand molecular mechanisms involved in the release of cytochrome $c$.

zVAD-Fmk, which completely blocked the apoptosis and the activation of caspase-8, had no effect on the release of cytochrome $c$, ruling out the involvement of caspases including caspase-8 and truncated Bid on mitochondrial events. This finding confirms that cytochrome $c$ release is upstream and independent of caspase activation.

In summary, DZA induced apoptosis in U-937 cells by activating a peculiar caspase cascade in that both caspase-dependent and -independent cascades were activated simultaneously, and caspase- 8 was activated downstream of caspase- 3 and caspase- 9 , serving as an executioner caspase. But, more definitive molecular experiments should be performed to investigate the exact mechanisms involved in the DZA-induced apoptosis. These studies will provide us good information about the caspase cascade and increase the therapeutic effectiveness of DZA and other anti-cancer drugs.

\section{Acknowledgements}

This study was supported by a grant of the Korea Health 21 R\&D Project, Ministry of Health \& Welfare, Republic of Korea (HMP-99-B-0-2002).

\section{References}

Akao Y, Otsuki Y, Kataoka S, Ito Y, Tsujimoto Y. Multiple subcellular localization of bcl-2: detection in nuclear outer membrane, endoplasmic reticulum membrane, and mitochondrial membranes. Cancer Res 1994;54(9):2468-71

Aksamit RR, Backlund PS, Cantoni GL. Chemotaxis and the synthesis of specific proteins are inhibited by 3-deazaadenosine and other adenosine analogs in a mouse macrophage cell line. J Biol Chem 1983;258:20-23

Aksamit RR, Backlund PS, Cantoni GL. Inhibition of chemotaxis by s-3-deazaadenosylhomocysteine in a mouse macrophage cell line. J Biol Chem 1982;257:621-25

Andreas S, Liam O, Vishva MD. Apoptosis signaling. Annu Rev Biochem 2000;69:217-45

Bernardi P, Scorrano L, Colonna R, Petronilli V, Lisa FD. Mitochondria and cell death. Eur J Biochem 1999;264:687-701

Beutner G, Ruck A, Riede B, Brdiczka D. Complexes between porin, hexokinase, mitochondrial creatine kinase and adenylate translocator display properties of the permeability transition pore: implication for regulation of permeability transition by the kinases. Biochim Biophys Acta 1998;1368:7-18

Chiang PK, Richards HH, Cantoni GL. S-Adenosyl-L-homocysteine hydrolase; analogues of S-adenosyl-L-homocysteine as potential inhibitors. Mol Pharmacol 1977;13:939-47

Cohen GM. Caspase: the executioners of apoptosis. Biochem J 1997;326:19-34

Crompton $\mathrm{M}$. The mitochondrial permeability transition pore and its role in cell death. Biochem J 1999;341:233-49

Cryn SV, Yuan J. Proteases to die for. Genes Dev 1998; 12:1551-70

Earnshaw WC, Martins LM, Kaufmann SH. Mammalian caspases: structure, activation, substrates, and functions during apoptosis. Annu Rev Biochem 1999;68:383-24

Engels $\mathrm{IH}$, Stepczynska A, Stroh C, Lauber K, Berg C, Schwenzer R, Wajant H, Jänicke RU, Porter AG, Belka C, Gregor M, Schulze-Osthoff K, Wesselborg S. Caspase-8/ FLICE functions as an executioner caspase in anticancer drug-induced apoptosis. Oncogene 2000;19:4563-73

Fadok VA, Henson PM. Apoptosis: getting rid of the bodies. Curr Biol 1998;8:R693-95

Flexner CW, Hildreth J, Kuncl RW, Drachman DB. 3-Deazaadenosine and inhibition of HIV. Lancet 1992;339:38

Friesen C, Herr I, Krammer PH, Debatin KM. Involvement of the CD95 (APO-1/Fas) receptor/ligand system in drug-induced apoptosis in leukemia cells. Nature Med 1996;2:574-77

Fulda S, Sieverts H, Friesen C, Herr I, Debatin KM. The CD95 (APO-1/Fas) system mediates drug-induced apoptosis in neuroblastoma cells. Cancer Res 1997;57:3823-29

Fulda S, Strauss G, Meyer E, Debatin KM. Functional CD95 ligand and CD95 death-inducing signaling complex in activation-induced cell death and doxorubicin-induced apoptosis in leukemic T cells. Blood 2000;95:301-8

Grubb DR, Ly JD, Vaillant F, Johnson KL, Lawen A. Mitochondrial cytochrome $\mathrm{c}$ release is caspase-dependent and does not involve mitochondrial permeability transition in didemnin B-induced apoptosis. Oncogene 2001;20:4085-94

Genini D, Adachi S, Chao Q, Rose DW, Carrera CJ, Cottam HB, Carson DA, Leoni LM. Deoxyadenosine analogs induce programmed cell death in chronic lymphocytic leukemia cells by damaging the DNA and by directly affecting the mitochondria. Blood 2000;96:3537-42

Hengartner OM. The biochemisty of apoptosis. Nature 2000; 407:770-76

Jacotot E, Ravagnan L, Loeffler M, Ferri KF, Vieira HL, Zamzami N, Costantini P, Druillennec S, Hoebeke J, Briand JP, Irinopoulou T, Daugas E, Susin SA, Cointe D, Xie ZH, Reed JC, Roques BP, Kroemer G. The HIV-1 viral protein R induces apoptosis via a direct effect on the mitochondrial permeability transition pore. J Exp Med 2000;191:33-46

Jeong SY, Ahn SG, Lee JH, Kim HS, Kim JW, Rhim H, Jeong SW, Kim IK. 3-Deazaadenosine, a s-adenosylhomocysteine 
hydrolase inhibitor, has dual effects on NF-KB regulation. $\mathrm{J}$ Biol Chem 1999;274:18981-88

Jeong SY, Lee JH, Kim HS, Hong SH, Cheong CH. Kim IK. 3-Deazaadenosine analogues inhibit the production of tumor necrosis factor-alpha in RAW264.7 cells stimulated with lipopolysaccharide. Immunology 1996;89:558-62

Kerr JFR, Wyllie AH, Currie AR. Apoptosis: a basic biological phenomenon with wide-ranging implications in tissue kinetics. Br J Cancer 1972;26:239-57

Kim HS, Jeong SY, Lee JH, Kim BE, Kim JW, Jeong SW, Kim IK. Induction of apoptosis in human leukemia cells by 3deazaadenosine is mediated by caspase-3-like activity. Exp Mol Med 2000;32:197-203

Kim IK, Li CCH, Young HA, Lee JH, Kim HS, Pardhasaradhi K, Garcia GE, Chiang PK. Apoptosis of L1210 leukemia cells induced by 3-deazaadenosine analogs: differential expression of c-myc, NF-кB and molecular events. J Biomed Sci 1997; 4:83-90

Krenitsky TA, Rideout JL, Chao EY, Koszalka GW, Gurney F, Crouch RC, Cohn NK, Wolberg G, Vinegar R. Imidazo [4,5c]pyridines (3-deazapurines) and their nucleosides as immuno suppressive and anti-inflammatory agents. J Med Chem 1986;29:138-43

Kroemer G, Reed JC. Mitochondrial control of cell death. Nature Med 2000;6(5):513-19

Kruidering M, Evan GI. Caspase-8 in apoptosis: the beginning of "the end"?. IUBMB Life 2000;50:85-90

Kumar S, Lavin MF. The ICE family of cysteine proteases as effectors of cell death. Cell Death Differ 1996;3:255-67

McGahon AJ, Pereira APC, Daly L, Cotter TG. Chemotherapeutic drug-induced apoptosis in human leukaemic cells is independent of the Fas (Apo-1/CD95) receptor/ligand system. Br J Haematol 1998;101:539-47

Medzihradsky JL. Regulatory role for the immune complex in modulation of phagocytosis by 3-deazaadenosine. J Immunol 1984;133:946-49

Morita Y, Siraganian RP, Tang CK, Chiang PK. Inhibition of histamine release and phosphatidyl-choline metabolism by $5^{\prime}-$ deoxy-5'-isobutyltho-3-deazaadenosine. Biochem Pharmacol 1982;31:2111-13

Mossmann T. Rapid colorimetric assay for cellular growth and survival: application to proliferation and cytotoxicity assays. $J$ Immunol Method 1983;5:55-63

Muzio M, Stockwell BR, Stennicke HR, Salvesen GS, Dixit VM. An induced proximity model for caspase-8 activation. J Biol Chem 1998;273:2926-30

Nagata S. Apoptosis by death factor. Cell 1997;88:355-65

Riches DWH, Watkins JL, Henson PH, Stanworth DR. Regulation of macrophage lysosomal secretion by adenosine, adenosine phosphate esters, and related structural analogues of adenosine. J Leukocyte Biol 1985;37:545-57

Scaffidi C, Fulda S, Srinivasan A, Friesen C, Li F, Tomaselli KJ, Debatin KM, Krammer PH, Peter ME. Two CD95 (APO/ Fas) signaling pathways. EMBO J 1998;17:1675-87
Slee EA, Herte MT, Kluck RM, Wolf BB, Casiano CA, Newmwyer DD, Wang HG, Reed JC, Nicholson DW, Alnemri ES, Green DR, Martin SJ. Ordering the cytochrome c-initiated caspase cascade: hierarchical activation of caspases-2, -3, $-6,-7,-8$, and -10 in a caspase-9-dependent manner. J Cell Biol 1999;144:281-92

Srinivasula MS, Manzoor A, Teresa FA, Gerald L, Emad SA. Molecular ordering of the Fas-apoptotic pathway: the Fas/ APO-1 protease Mch5 is a crmA-inhibitable protease that activates multiple ced-3/ICE-like cysteine proteases. Proc Natl Acad Sci USA 1996;93:14486-91

Stennicke HR, Deveraux QL, Humke EW, Reed JC, Dixit VM, Salvesen GS. Caspase- 9 can be activated without proteolytic processing. J Biol Chem 1999;274:8359-62

Stennicke HR, Jürgensmeier JM, Shin H, Deveraux $Q$, Wolf BB, Yang X, Zhou Q, Ellerby HM, Ellerby LM, Bredesen D, Green DR, Reed JC, Froelich CJ, Salvesen GS. Pro-caspase3 is a major physiologic target of caspase-8. J Biol Chem 1998;273:27084-90

Stennicke HR, Salvesen GS. Properties of the caspases. Biochimica Biophysica Acta 1998;1387:17-31

Sun XM, MacFarlane M, Zhuang J, Wolf BB, Green DR, Cohen GM. Distinct caspase cascades are initiated in receptor-mediated and chemical-induced apoptosis. J Biol Chem 1999;274:5053-60

Tepper AD, Vries E, Blitterswijk WJ, Borst J. Ordering of ceramide formation, caspase activation, and mitochondrial changes during CD95- and DNA damage-induced apoptosis. $\mathrm{J}$ Clin Invest 1999;103:971-78

Tolomeo M, Dusonchet L, Meli M, Grimaudo S, Alessandro ND, Papoff G, Ruberti G, Rausa L. The CD95/CD95 ligand system is not the major effector in anticancer drug-mediated apoptosis. Cell Death Differ 1998;5:735-42

Vaux DL, Strasser, A. The molecular biology of apoptosis. Proc Natl Acad Sci USA 1996;93:2239-44

Wieder T, Essmann F, Prokop A, Schmeiz K, Schulze-Osthoff $\mathrm{K}$, Beyaert R, Dörken B, Daniel PT. Activation of caspase-8 in drug-induced apoptosis of B-lymphoid cells is independent of CD95/Fas receptor-ligand interaction and occurs downstream of caspase-3. Blood 2001;97:1378-87

Woodfield K, Ruck A, Brdiczka D, Halestrap AP. Direct demonstration of a specific interaction between cyclophilin-D and the adenine nucleotide translocase confirms their role in the mitochondrial permeability transition. Biochem J 1998;336: 287-90

Wyllie AH, Kerr JFR, Currie AR. Cell death: the significance of apoptosis. Int Rev Cytol 1980;68:251-306

Yagawa K, Nakanishi M, Hayashi S, Kaku M, Ichinose Y, Itoh T, Tomoda A, Yoneyama Y, Shigematsu N. Abolishment of inhibitory effects of 3-deazaadenosine on superoxide generation of guinea pig phagocytes by pre-exposure to phorbol myristate acetate. FEBS Lett 1986;201:287-90

Zimmerman TP, Wolberg G, Duncan GS. Inhibition of lymphocyte-mediated cytolysis by 3-deazaadenosine: evidence for a methylation reaction essential to cytolysis. Proc Natl Acad Sci USA 1978;75:6220-24 